\title{
Research on Construction Methods for Ultralarge Y-Shaped Tunnel Sections
}

\author{
Shiding Cao $\mathbb{D},{ }^{1}$ Yongli Xie, ${ }^{1}$ Wei Tang, ${ }^{1}$ Wei Wang, ${ }^{2}$ Qianru Zhou, ${ }^{1}$ and Aipeng Guo $\mathbb{D}^{3}$ \\ ${ }^{1}$ Shenzhen Transportation Degish \& Research Institute Co., Ltd., Shenzhen 518003, China \\ ${ }^{2}$ Building \& Materials Industry Management Office of Minhang District, Shanghai 201100, China \\ ${ }^{3}$ State Key Laboratory for Geomechanics and Deep Underground Engineering, \\ China University of Mining \& Technology (Beijing), Beijing 100083, China \\ Correspondence should be addressed to Aipeng Guo; guoaipeng0422@163.com
}

Received 17 March 2021; Revised 9 April 2021; Accepted 17 April 2021; Published 26 April 2021

Academic Editor: Qingxiang Meng

Copyright (C) 2021 Shiding Cao et al. This is an open access article distributed under the Creative Commons Attribution License, which permits unrestricted use, distribution, and reproduction in any medium, provided the original work is properly cited.

\begin{abstract}
Many problems are encountered in the construction of bifurcated tunnels due the abrupt change in section, small clear distance, and large section. Progress in the direction of tunnel construction is limited by the large-span section; therefore, a special method of construction that involves constructing a guiding tunnel first followed by reverse excavation was adopted to construct the large-span bifurcation section of the Liantang tunnel of Shenzhen Eastern Transit Expressway in China. The stability criterion of the surrounding rock of the middle wall in the section of multiple arch and small clear distance is studied by theoretical analysis, and the internal stress and corresponding ultimate strength of the middle wall under different buried depths and widths of the middle wall are calculated by the stability criterion. In this study, 3D finite-difference software was used to simulate the excavation process under forward and reverse excavation conditions. The results show that the displacement field and internal force field distribution are similar for both excavation methods, and the tunneling first and reverse excavation construction method is safe and reliable.
\end{abstract}

\section{Introduction}

With the development and utilization of urban underground space, the urban underground has become a complex system of crisscrossing tunnels and pipe corridors. Taking into account space constraints and the influence of other factors such as engineering costs and line smoothness, $y$-shaped connections, i.e., bifurcated tunnels, are typically adopted in underground tunnel systems $[1,2]$. Due to the abrupt change in shape of the bifurcated tunnel section, which transitions from a double-line parallel small section to a single-line large section, combined with the original special structure of the small clear-distance (or double-arch) tunnel and largesection tunnel, the overall forces acting on the bifurcated tunnel are complicated, and the construction process is difficult $[3,4]$. Therefore, construction of the bifurcation point has always been an important consideration in the design and construction of bifurcated tunnels.
$\mathrm{Bi}$ and $\mathrm{Wu}$ [5] used the MIDAS/GTS finite element software to analyze different cross section types of bifurcated tunnels, with or without a continuous arch section, to select optimal anchor rod layout. Liu and Qi [6] used numerical simulation methods to compare and optimize five construction methods from 4-step to 8-step excavation using the bifurcation section of the Qingdao Jiaozhou Bay submarine highway tunnel as a model. Jing et al. [7] introduced a series of construction and excavation methods for different bifurcated sections of the Xiangjiang Tunnel on Yingpan Road in Changsha, China, and elaborated on key construction techniques for gradually changing sections and the specialshaped secondary lining. Yang and Li [8]. performed a threedimensional finite element analysis of the bifurcation section of the Shuangjiang Tunnel underpassing an existing building project, discussed the internal forces in the lining structure, and combined building foundation settlement data, building deformation control standards, and the existing research 
data to evaluate the deformation response of existing buildings to the tunnel construction. Liu [9] used engineering analogy, numerical simulation, and other means to determine a reasonable length of the small clear-distance cross-tunnel section with lining stress and surrounding rock plastic zone as the criteria for realizing safe construction of a shallow-buried bifurcated tunnel.

Other scholars have conducted similar research through different research methods. Meng et al. [10] developed DigiSim and studied the characteristics of rock microstructure. Tao et al. studied the reinforcement measures and supporting effects of large-scale antidipping slopes [11-13]. Wang et al. [14] studied the evolution law and failure mechanism of rock cracks. Li et al. [15] studied and analyzed the boundary conditions and mechanical behavior of rock in the shearing process. Wang and others conducted field tests in tunnels based on digital drilling engineering and proposed an evaluation method for bolt grouting design [16]. Wang et al. [17] studied the mechanized construction of largediameter tunnels through field tests. Li et al. [18] studied the stability evaluation of underground chamber sidewalls through theoretical derivation and numerical simulation.

To reduce the construction risk and operational difficulty caused by a sudden change in cross section, bifurcated tunnels are usually constructed in sequence, starting with the large section followed by construction of the small sections. Large-section tunnels are generally constructed using the double-side heading method or cross diaphragm (CRD) method. However, due to the large number of temporary supports required and the complexity of the process, the construction efficiency is low and daily footage is typically within the range of $0.5 \mathrm{~m}$ to $1 \mathrm{~m}$ [19]. Therefore, in the construction of bifurcated tunnels, it is often not possible to excavate in the direction of the small section due to insufficient progress in construction the long-span section, which can lead to significant construction delays.

In this paper, we consider the Liantang y-shaped bifurcated tunnel section of the Shenzhen East Transit Expressway Connection Line Project and discuss the proposed bifurcated tunnel construction method of pilot tunnel first and reverse excavation. Through a comparative analysis with the original excavation design plan, the practical experience of the construction sequence of the bifurcated tunnel excavation is summarized.

1.1. Tunnel Construction Project Overview. The total length of the Liantang large-span bifurcated tunnel in Shenzhen East Transit Expressway Connection Project II is $173.029 \mathrm{~m}$. The 3-lane main line merges with the 2-lane Liantang port connecting the RO line and becomes a 4-lane main line with a design speed of $80 \mathrm{~km} / \mathrm{h}$. The starting and ending pile numbers of the tunnel are NXK2 + 810 and NXK2 + 983.029 and the maximum excavation span is $29.874 \mathrm{~m}$.

From bottom to top, strata at the tunnel site is comprised of a carboniferous metamorphic sandstone layer, quaternary residual layer $\left(\mathrm{Q}^{\mathrm{el}}\right)$, quaternary Upper Pleistocene slope diluvial layer $\left(\mathrm{Q}^{3 \mathrm{dl}+\mathrm{pl}}\right)$, and the quaternary Upper Pleistocene alluvial layer $\left(\mathrm{Q}^{3 \mathrm{al}+\mathrm{pl}}\right)$, quaternary Holocene alluvial layer $\left(\mathrm{Q}^{4 \mathrm{al}+\mathrm{pl}}\right)$, and artificial fill layer $\left(\mathrm{Q}^{\mathrm{ml}}\right)$. The rock surrounding the tunnel body is slightly weathered metamorphic sandstone with good integrity and some broken rock. The surrounding rock grades are Grade II and Grade III.

The tunnel section is composed of a small, clear-distance section, multiarch section, and five large-span sections A-E. The supporting parameters of the large-span section A before the tunnel merges and the small, clear-distance section after the tunnel merges are presented in Table 1 and Figure 1.

\section{Stability Criterion and Reasonable Thickness of Middle Wall}

2.1. Theoretical Analysis of Middle Wall Stability. The results of the theoretical analysis show that the loads on the middle wall of the twin arch tunnel and small spacing tunnel are related to the gravity of the overlying rock mass between the center lines of the left and right tunnels [20]. The mechanical model of the partition wall under load is shown in Figure 2.

$$
P=\gamma H(a+2 b) L
$$

where $\gamma$ is the average unit weight of the overlying strata $\left(\mathrm{MN} / \mathrm{m}^{3}\right), H$ is the thickness of the overlying strata, $b$ is the distance from the middle line of the tunnel on one side to the middle wall, $a$ is the width of the middle wall, and $L$ is the length of the middle wall. Then the stress in the middle wall is

$$
\sigma=\mathrm{K} \frac{\gamma H(a+2 b) L}{a L}=K \gamma H A,
$$

where $K$ is the stress correction factor of the middle wall, $A=((a+2 b) / a)$.

According to the maximum normal stress theory of classical rock strength theory, when the present formula is established, the structure is stable; otherwise the structure is unstable:

$$
\sigma<[\sigma]
$$

where $[\sigma]$ is the ultimate strength.

The concrete middle wall of a multiarch tunnel can be simplified as a uniaxial specimen loaded up and down; that is, the ultimate strength of concrete $R_{b}$ is taken as the ultimate strength $[\sigma]$. Substituting (2) into (3), the stability criterion of concrete middle wall is

$$
K \gamma H A<R_{b}
$$

According to the limit equilibrium criterion, the ultimate strength of the middle wall of a tunnel with small spacing is

$$
[\sigma]=\frac{2 c \cos \varphi}{1-\sin \varphi}+\frac{1+\sin \varphi}{1-\sin \varphi}\left(\eta \gamma H+\frac{P}{\mathrm{RL}}\right),
$$

where $c$ is the cohesion, $\varphi$ is the internal friction angle, $\eta$ is the horizontal lateral pressure coefficient, $P$ is the prestress of the bolt support, and $R$ and $L$ are the row spacing and spacing of the split bolt through the middle wall, respectively. 
TABLE 1: Technical specifications for supporting parameters of partial sections of the Liantang large-span bifurcated tunnel.

\begin{tabular}{|c|c|c|c|}
\hline Lining type & Large-span section A & Main line of multiarch section & $\begin{array}{c}\text { Connecting RO line at Liantang port in } \\
\text { multiarch section }\end{array}$ \\
\hline $\begin{array}{l}\text { Anchor } \\
\text { setting }\end{array}$ & $\begin{array}{l}\text { RM28 prestressed anchor; } L=8.0 \mathrm{~m} ; \\
\text { spacing } 0.7 \times 1.0 \mathrm{~m}\end{array}$ & $\begin{array}{c}\varphi 25 \text { cartridge bolt; } L=3.5 \mathrm{~m} \text {, spacing } \\
1.0 \times 1.0 \mathrm{~m}\end{array}$ & $\begin{array}{c}\varphi 25 \text { cartridge bolt, } L=3.5 \mathrm{~m} \text {, spacing } \\
1.0 \times 1.0 \mathrm{~m}\end{array}$ \\
\hline $\begin{array}{l}\text { Initial } \\
\text { support }\end{array}$ & $\begin{array}{c}\text { C30 shotcrete, thickness } 35 \mathrm{~cm} ; \varphi 8 \text { steel } \\
\text { mesh, spacing } 20 \times 20 \mathrm{~cm} ; \mathrm{I} 25 \mathrm{~b} \text { steel } \\
\text { arch frame; spacing } 70 \mathrm{~cm}\end{array}$ & $\begin{array}{l}\text { C30 shotcrete, thickness } 22 \mathrm{~cm} ; \varphi 8 \text { steel } \\
\text { mesh, spacing } 20 \times 20 \mathrm{~cm} ; \mathrm{I} 16 \text { steel arch } \\
\text { frame, spacing } 100 \mathrm{~cm}\end{array}$ & $\begin{array}{l}\text { C30 shotcrete, thickness } 22 \mathrm{~cm} ; \varphi 8 \text { steel } \\
\text { mesh, spacing } 20 \times 20 \mathrm{~cm} \text {; I16 steel arch } \\
\text { frame, spacing } 100 \mathrm{~cm}\end{array}$ \\
\hline Secondary & C35 reinforced concrete; thickness & C35 reinforced concrete; thickness & C35 reinforced concrete; thickness \\
\hline lining & $70 \mathrm{~cm}$ & $45 \mathrm{~cm}$ & $40 \mathrm{~cm}$ \\
\hline
\end{tabular}

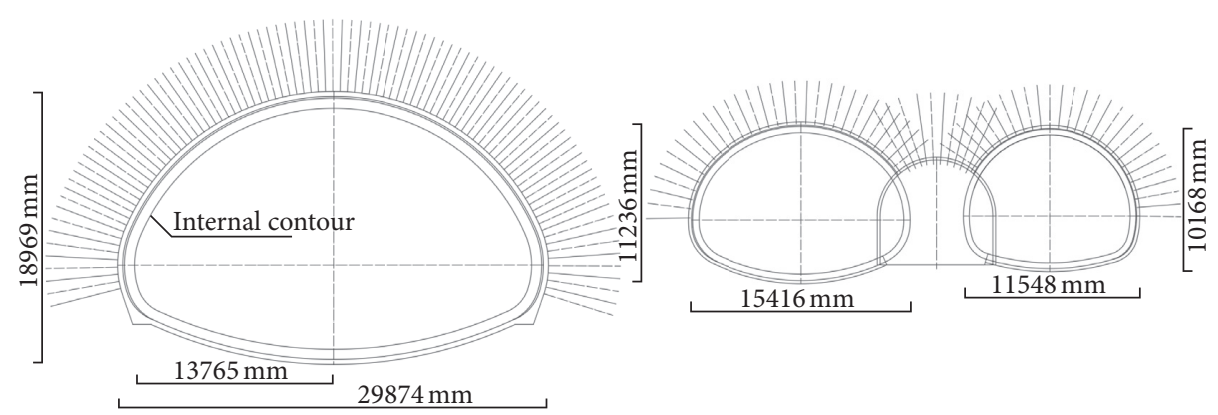

Figure 1: Sectional dimensions of large-span A-shaped and multiarch sections of bifurcated tunnels.

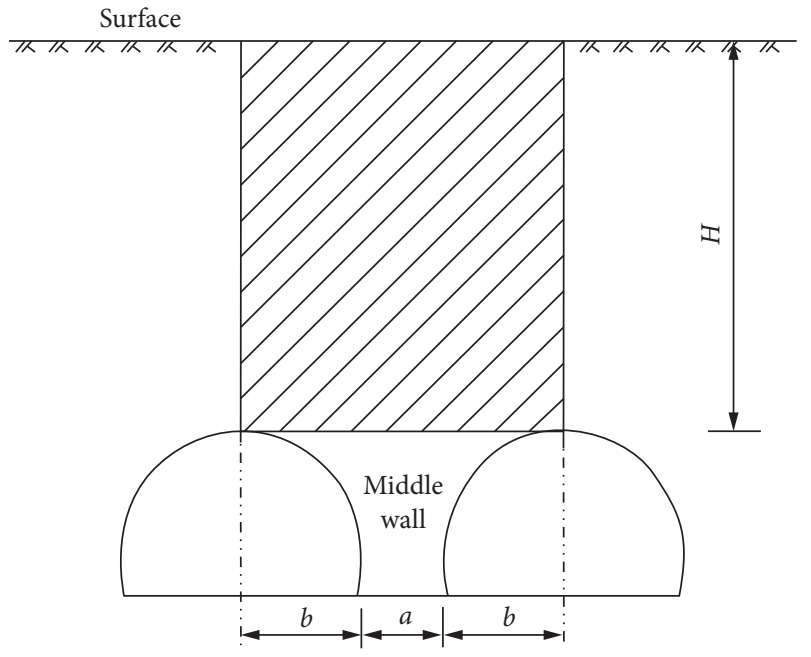

FIGURE 2: Stress mode of middle wall.

For tunnels with small clear distance, the stability criterion can be obtained by combining (2) and (5), as follows [20]:

$$
K \gamma H A<\frac{2 c \cos \varphi}{1-\sin \varphi}+\frac{1+\sin \varphi}{1-\sin \varphi}\left(\eta \gamma H+\frac{P}{\mathrm{RL}}\right) .
$$

Equation (6) shows that the stability of the middle wall with small spacing can be improved by adjusting the values of $c$ and $\varphi$ of the middle wall through reinforcement measures and increasing the side pressure of the middle wall using prestressed anchor bolts through the middle wall. Thus far, the stability criteria of the double-arch tunnel and small-distance tunnel can be obtained, and a reasonable thickness of the middle wall can be obtained according to the formula.
2.2. Calculation of Reasonable Thickness of Partition Wall. Now the application of the Liantang bifurcated tunnel's continuous arch section and small clear-distance section is explained. The excavation width of the single tunnel of the tunnel is $15.716 \mathrm{~m}$ and $12.26 \mathrm{~m}$, and the lateral pressure coefficient is 0.35 ; the bulk density of the surrounding rock of the tunnel is $24 \mathrm{kN} / \mathrm{m}^{3}$, the cohesive force $c$ is $1.1 \mathrm{MPa}$, and the internal friction angle $(\varphi)$ is $44^{\circ}$ in the multiarch tunnel. The middle wall is made of C30 concrete, and the ultimate strength $R_{b}$ is $21 \mathrm{MPa}$; the small clear-distance middle wall is not supported by prestressed anchors. Figure 3 shows the internal stress and the corresponding ultimate strength of the middle wall under different buried depths and different widths of the middle wall calculated according to the stability criterion.

From the calculation results in Figure 1, it can be concluded that, for a multiarch tunnel, when the width of the partition wall is $1.0 \mathrm{~m}$, the buried depth below $125 \mathrm{~m}$ can remain stable. When the width of the middle wall of the small clear tunnel is $3.2 \mathrm{~m}$, the buried depth below $125 \mathrm{~m}$ can maintain stability.

\section{Design of Excavation Scheme and Change of Intersection Point}

3.1. Design of Excavation Scheme for Forward Excavation. To reduce construction risk and ensure safety during construction of the large-span section, the original design required that the tunnel face space provided by the main line tunnel of the Eastern Transit Expressway be used during the construction of the Liantang bifurcated section tunnel, and construction was carried out from large mileage to small mileage. The specific steps of the excavation process were as follows: 


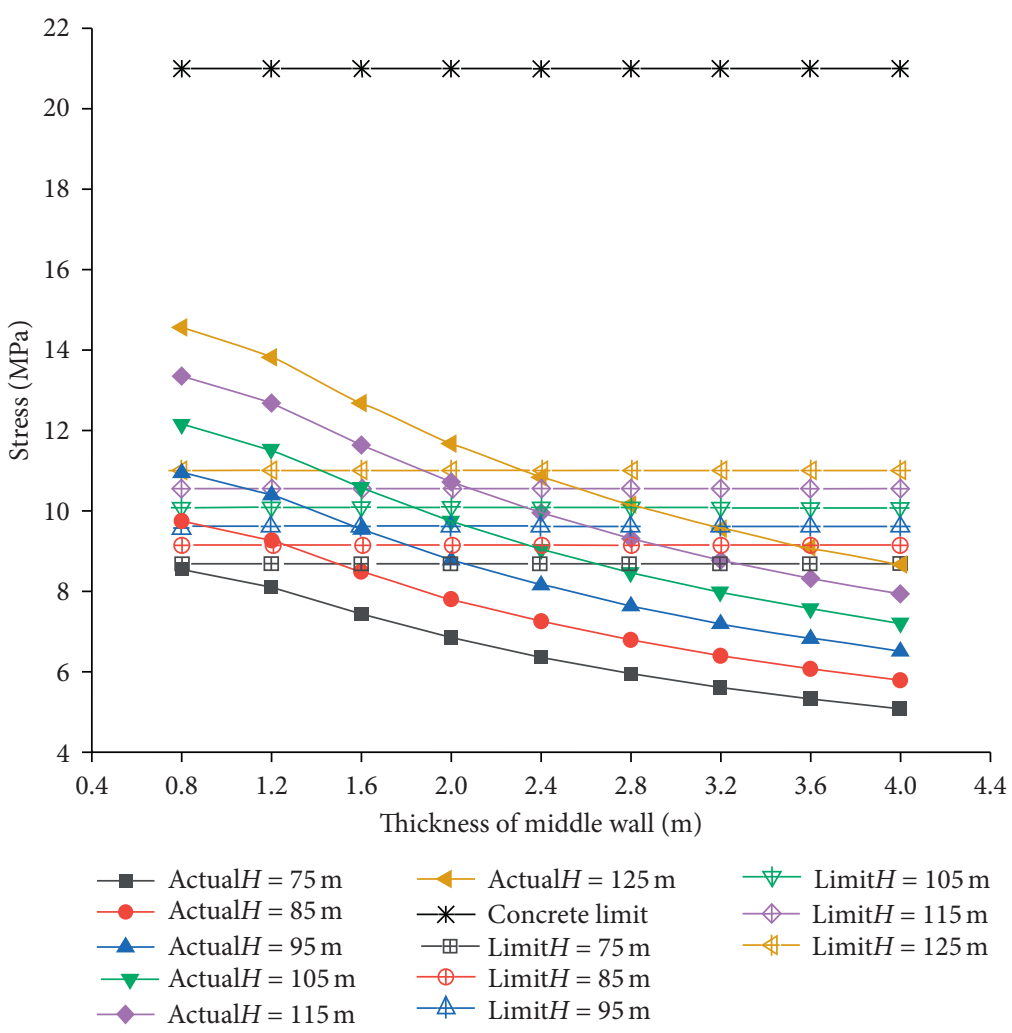

FIGURE 3: Internal stress and ultimate strength of the partition wall under different buried depths and widths.

(1) Step 1: the double-side wall pilot pit method was used to construct large-span sections $E, \mathrm{D}, \mathrm{C}, \mathrm{B}$, and $A$ and the joint head wall in sequence, as indicated by the gray area in Figure 4(a).

(2) Step 2: after completion of the secondary lining of the large-span section, the pilot tunnel was excavated and used as a partition wall, as shown by the brown area of Figure $4(\mathrm{a})$.

(3) Step 3: the upper and lower steps method was used to construct the multiarch section and the small, cleardistance section of the Liantang Port connecting RO line, shown as the red area in Figure 4(a).

(4) Step 4: The three-step method was used to construct the multiarch section of the main line tunnel, as indicated by the purple area in Figure 4(a).

(5) Step 5: The small, clear-distance section of the main line tunnel was constructed using the up and down step method, as illustrated by the green area in Figure 4(a).

3.2. Implementation of Reverse Excavation Construction. The advantages and disadvantages of bifurcated tunnels for forward and reverse excavation are shown in Table 2. Based on the actual progress of the site, the bifurcated tunnel section cannot be constructed from large to small mileage according to the original design. To ensure smooth progress of the project, the following changes to the construction process are proposed:
(1) Step 1: From mileage NXK2 +810 (the starting point of the main line of the small, clear-distance section), excavate the first left pilot hole along the large mileage direction to NXK2 +920.531 (the junction of large-span $\mathrm{E}$ and $\mathrm{D}$ ), as shown by the white area in Figure 4(b). The pilot tunnel can also be used as a slag channel for initial, temporary support.

(2) Step 2: After $8 \mathrm{~m}$ of the pilot tunnel have been excavated along the direction of the large mileage, the excavation can be expanded to form a complete design section for initial support, as indicated by the yellow area in Figure 4(b).

(3) Step 3: The double-side-wall pilot method can be used to construct the tunnel along the direction of the large mileage until a sufficient reverse excavation construction space is formed, as shown by the gray area in Figure 4(b).

(4) Step 4: The large-span sections D-A of the right pilot tunnel are excavated for initial, temporary support, shown by the green area in Figure 4(b). Then, the double-side pilot tunnel method is used to simultaneously excavate the remaining sections of the large-span E section, shown as the blue area in Figure 4(b).

(5) Step 5: The middle rock pillar of large-span sections $\mathrm{D}-\mathrm{A}$ is excavated and the initial support is closed into a ring, as shown by the brown area in Figure 4(b). 


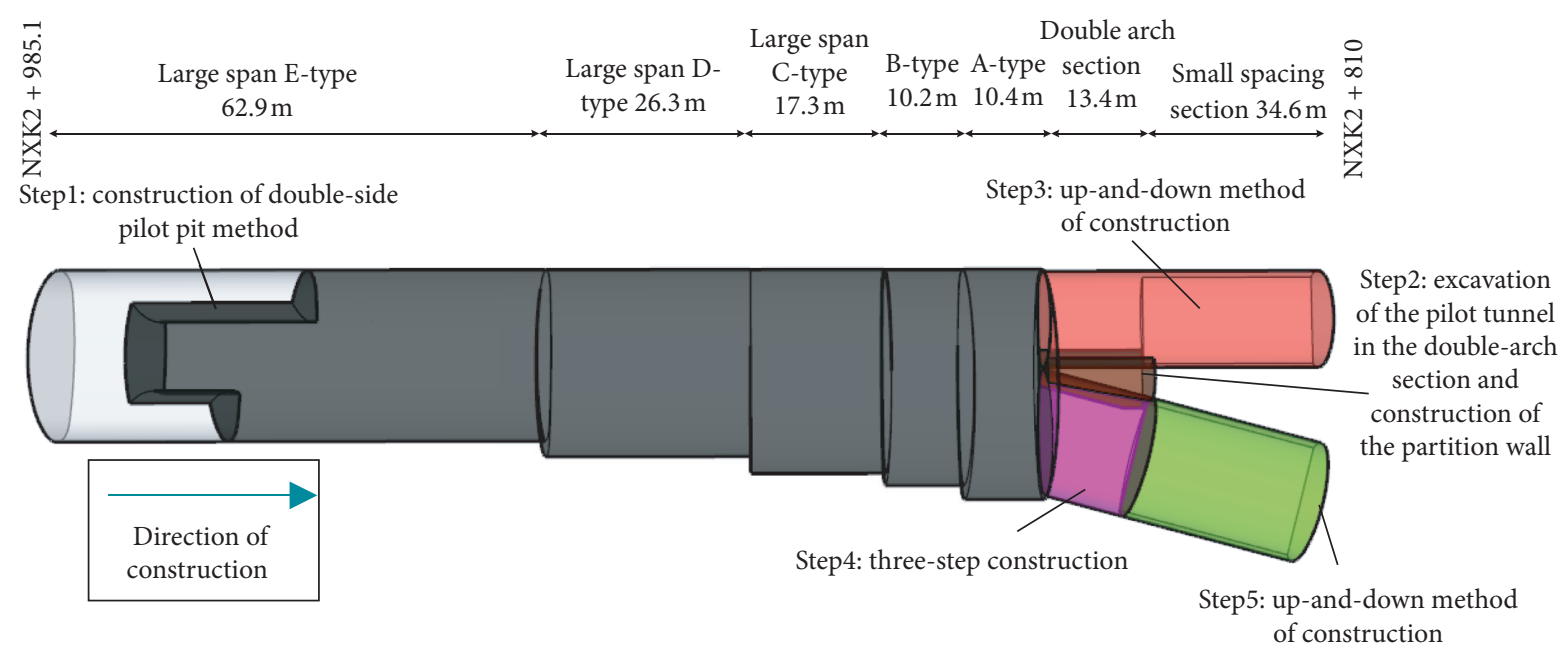

(a)

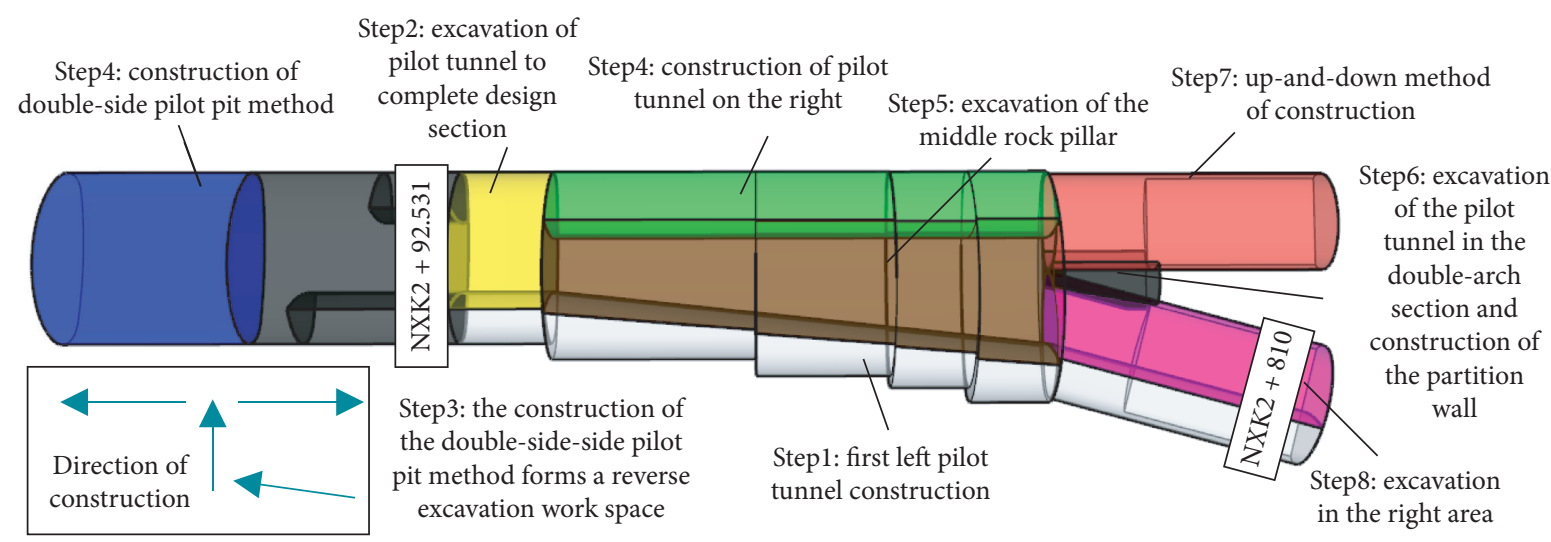

(b)

FIgURE 4: Comparison of concrete steps for forward and reverse excavation of bifurcated tunnel. (a) Forward excavation. (b) Reverse excavation.

(6) Step 6: After constructing large-span section A and the second lining is complete, the pilot tunnel is excavated and constructed as a partition wall, shown as the black area in Figure 4(b).

(7) Step 7: The multiarch section and Liantang port connecting RO line of the small clear-distance section are constructed according to the original design plan, indicated by the red area in Figure 4(b).

(8) Step 8: The multiarch section and the remaining part on the right side of the main line of the small, clear-distance section are shown in purple in Figure 4(b).

\subsection{Simulation of Bifurcation Tunnel Construction Process.} The FLAC 3D finite-difference software was used to numerically analyze the original forward excavation plan and pilot tunnel first reverse excavation plan. Solid elements were selected for the surrounding rock and the initial support. Shell elements were used for the secondary lining. Simulation of the excavation process was realized by unit creation or attribute change. The excavation methods and construction procedures of each section were set using the original direct excavation design plan and the pilot tunnel first reverse excavation construction plan to be implemented on-site.

The surrounding rock strata at the location of the bifurcated tunnel are in good condition and the buried depth was greater than $85 \mathrm{~m}$; therefore, surface undulation will have little effect on the numerical analysis results. Based on the geological prospecting data, the surrounding rock strata was simplified as overlying grade IV rock with a thickness of $40 \mathrm{~m}$ and underlying grade III rock with a thickness of $162.6 \mathrm{~m}$.

The total length of the Liantang large-span bifurcated tunnel section exceeds $170 \mathrm{~m}$. To reduce the complexity of the model and computational load, $71.3 \mathrm{~m}$ was intercepted to establish the three-dimensional numerical model, as shown in Figure 5. In contrast to the on-site implementation plan, in the simulation process, the pilot tunnel was excavated to section C; then, the reverse excavation was started. Although the position is about $20 \mathrm{~m}$ away from the location of sudden change in cross section at the junction point, this had little effect on the final numerical results. 
TABLE 2: Comparison of advantages and disadvantages of forward and reverse excavation of bifurcated tunnel.

\begin{tabular}{l}
$\begin{array}{l}\text { Construction } \\
\text { method }\end{array}$ \\
\hline (1) The construction proceeds in a single direction and the \\
construction process is relatively simple.
\end{tabular}

Forward excavation

(2) The construction sequence proceeds from the large to small section at the junction, and the construction risk and difficulty are lower.

(1) Construction proceeds from small mileage to large mileage, followed by reverse excavation; therefore, the tunneling speed is not limited by the speed of constructing the large-span section of the main line.

Reverse excavation

(2) Two-way construction can be realized, which speeds up the construction process, to a certain extent.
(1) The construction speed is slow for the large-span section of the main line. If construction proceeds from a large mileage to a small mileage, the construction process will be delayed.

(2) It is not possible to realize two-way construction or eliminate delays in construction.

(1) The construction direction changes many times, the construction process is complicated, and influence on the surrounding rock is unknown.

(2) Mutation stress concentrations in the cross section of the pilot tunnel at the junction makes construction more difficult and higher risk

(3) The extension section of the pilot tunnel has a tunnel span of more than $20 \mathrm{~m}$ and there are certain construction difficulties and risks

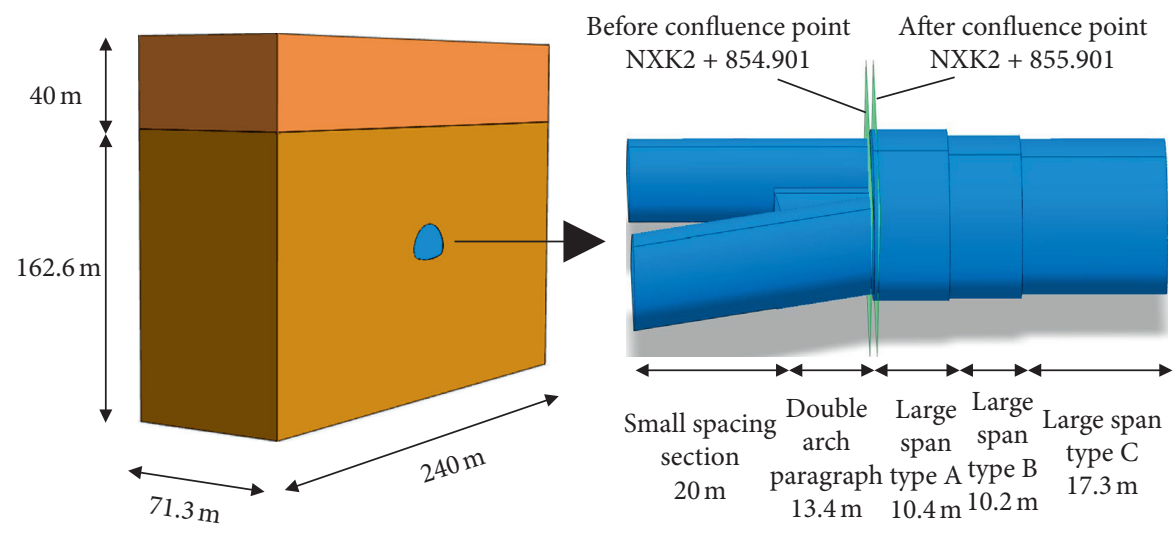

FIgURE 5: Three-dimensional numerical calculation model of Liantang bifurcated tunnel.

The cross-sectional size of the numerical analysis model was selected by considering the influence of the constraint conditions on the excavation process and according to the Saint-Venant principle, the left and right boundaries were about 4 times the maximum width of the tunnel model and horizontal displacement was constrained; the lower boundary was about 3.5 times the maximum height of the tunnel model from the bottom of the tunnel and vertical displacement was constrained; the upper boundary was set as a free surface without displacement constraints.

The Moore Coulomb model was selected for the surrounding rock material, the elastic model was selected for the initial support and the secondary lining, and the calculation parameters were selected according to the geological prospecting data and recommended values of the codes are listed in Table 3.

\section{Analysis of Results and Discussion}

4.1. Comparative Analysis of Surrounding Rock Displacement. Figures 6(a) and 6(b) show the vertical displacement nephograms of the supporting structure under different
TABLE 3: Surrounding rock and supporting structure parameters used in numerical model.

\begin{tabular}{lccccc}
\hline Material & $\begin{array}{c}E \\
(\mathrm{MPa})\end{array}$ & $\begin{array}{c}\gamma \\
\left(\mathrm{kN} / \mathrm{m}^{3}\right)\end{array}$ & $\nu$ & $\varphi /^{\circ}$ & $\begin{array}{c}c \\
(\mathrm{kPa})\end{array}$ \\
\hline $\begin{array}{l}\text { Grade III surrounding } \\
\text { rock }\end{array}$ & 10700 & 24.0 & 0.26 & 44 & 1100 \\
$\begin{array}{l}\text { Grade IV surrounding } \\
\text { rock }\end{array}$ & 3100 & 21.5 & 0.32 & 32.5 & 400 \\
$\begin{array}{l}\text { Initial support } \\
\text { Secondary lining }\end{array}$ & 25000 & 22 & 0.2 & - & - \\
\hline
\end{tabular}

Notes: $E$-elastic modulus; $\gamma$-volume weight; $\nu$-Poisson's ratio; $\varphi$-internal friction angle; $c$-cohesion.

working conditions after construction of the bifurcated tunnel. The vertical displacement of the lining is similar under both conditions, especially in the region of the vault settlement area of each section. The extreme values of the dome settlement are $19.51 \mathrm{~mm}$ and $19.47 \mathrm{~mm}$, respectively. Therefore, from a relatively broad point of view, the reverse excavation scheme has a similar impact on vault settlement as the original excavation scheme. 


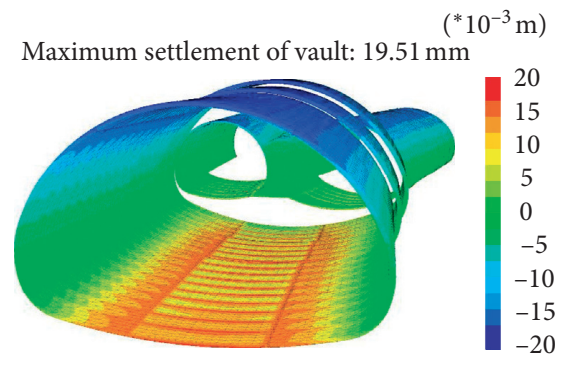

(a)

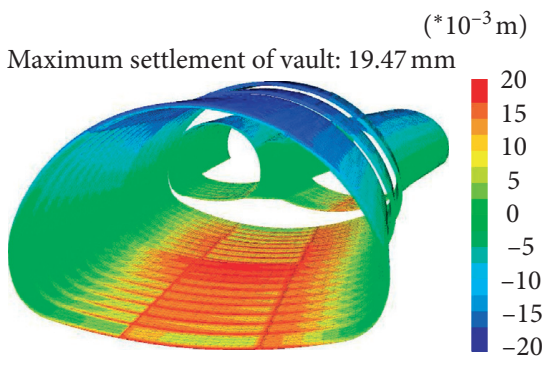

(b)

FIGURE 6: Comparison of displacement nephograms for two different excavation conditions. (a) Forward excavation of large-span section. (b) Reverse excavation of large-span section.

Furthermore, the numerical results for back excavation are close to the extreme vault settlement measurement of $20.04 \mathrm{~mm}$, indicating that the numerical results are reliable.

To further study the differences and similarities of the strata displacement distribution under the different excavation methods, typical sections NXK2 +854.901 (before confluence point) and NXK2 +855.901 (after confluence point) were selected for comparative analysis. The extreme settlement values of tunnel vault under two different working conditions are shown in Table 4 . The results show that there is little difference between the two working conditions of the NXK2+855.901 section, which are $14.29 \mathrm{~mm}$ and $14.24 \mathrm{~mm}$, respectively, and NXK2 + 854.901. The extreme value of the settlement of the arch crown under working condition 1 is slightly larger than that under the working condition 2; however, the difference is only $4.1 \%$.

The comparison shows that the influences of forward excavation (working condition 1) and reverse excavation (working condition 2) on the ground displacement field are basically the same.

Figure 7 shows the maximum principal stress cloud diagram of large-span, double-arch, and small clear-distance tunnels under the conditions of forward and reverse excavation. As shown in Figure 7(a), when using the direct excavation method, the stress concentration is the most serious and the concentration range is large at the side wall of the long-span tunnel, and the maximum principal stress value is $37.5 \mathrm{MPa}$. The degree of stress concentration at the arch waist and arch foot position is smaller than that at the side wall, and the maximum principal stress average is $18 \mathrm{MPa}$. There are also stress concentrations at the side wall and arch waist of the tunnel with small clear distance and multiarch sections. As shown in Figure 7(b), when the reverse excavation method is adopted, the stress concentration range at the side wall of the long-span tunnel is significantly reduced, and the stress concentration occurs in the transition area of the long-span section. The maximum principal stress value is $35 \mathrm{MPa}$, and the average maximum principal stress at the arch waist position of the long-span tunnel is $17.5 \mathrm{MPa}$. From the above comparison, it can be concluded that, with the reverse excavation method, the load-bearing load of the long-span section, the small clear-distance section, and the multiarch section of the tunnel is smaller than that of the direct excavation method, and the stress concentration range is significantly reduced.

4.2. Comparative Analysis of Internal Forces in Lining Structure. Internal forces in the secondary lining of a typical NXK2 + 855.901 section under two different working conditions were extracted and are listed in Table 5. A stress analysis was carried out at key positions such as the vault, arch waist, arch foot, and arch bottom, and the safety factor of the lining structure was calculated using the comprehensive safety factor method [21]. Within the lining, the axial force is positive in tension and the bending moment is positive in tension. The results in Table 5 suggest that characteristics of the internal force distribution of the secondary lining are similar for both excavation methods, and the bending moment and axial force values at the vault and arch bottom are smaller; however, the sudden change in cross section results in large internal forces at the right arch waist (the connection point with the main line tunnel lining of the multiarch section), left arch foot, and left arch waist (the connection point with the RO line lining). During tunnel construction, the internal force values should be monitored and controlled to prevent cracking of the lining. The safety factor of the lining is slightly higher under working condition 2; however, the difference is small, and the results are all within the safe limits. This suggests that the mechanical responses of the two excavation methods are basically the same, and the integrity of the lining structure can be guaranteed.

\section{Field Engineering Application}

According to the results of numerical simulation on the applicability of forward and reverse excavation construction method for bifurcated tunnel, the reverse excavation construction method is selected in the study area. Figure 8 shows the actual shooting of the on-site construction process.

The designed reverse excavation method was used to successfully complete the excavation of the bifurcation tunnel section. Through systematic observation, the field construction effect is close to the expected result. The surrounding rock always maintains a stable state during the excavation process, and the support measures and excavation methods have been effectively verified. 
TABLE 4: Extreme vault settlement values under two different working conditions (mm).

\begin{tabular}{lcc}
\hline \multirow{2}{*}{ Working condition } & \multicolumn{2}{c}{ Location of typical section } \\
& NXK2 +854.901 (before confluence point) & NXK2+855.901 (after confluence point) \\
\hline Working condition 1 & 14.29 & 16.39 \\
Working condition 2 & 14.24 & 15.74 \\
\hline
\end{tabular}

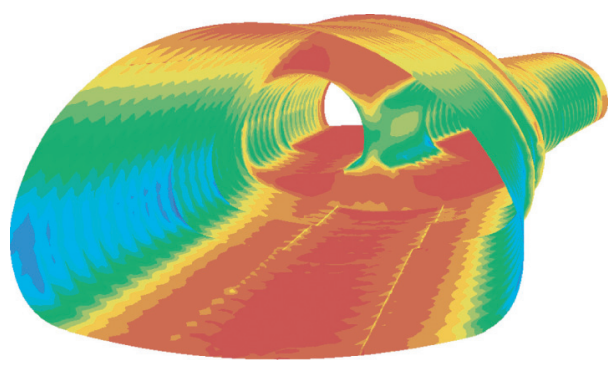

(a)

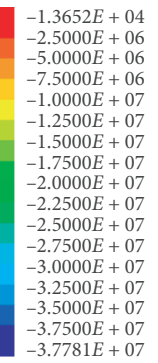

$-3.7500 E+07$

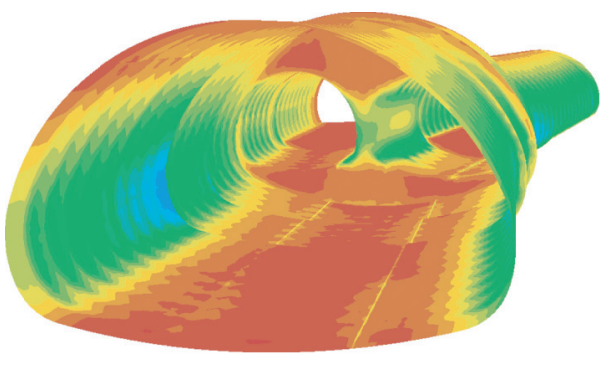

(b)

Figure 7: Contrast of maximum principal stress cloud diagram of positive and negative excavation. (a) Forward excavation of large-span section. (b) Reverse excavation of large-span section.

TABLE 5: Safety factor of secondary lining of tunnel.

\begin{tabular}{|c|c|c|c|c|c|c|c|}
\hline Working condition & Position & Arch roof & $\begin{array}{c}\text { Right arch } \\
\text { waist }\end{array}$ & $\begin{array}{l}\text { Right arch } \\
\text { foot }\end{array}$ & $\begin{array}{c}\text { Arch } \\
\text { bottom }\end{array}$ & Left arch foot & $\begin{array}{c}\text { Left arch } \\
\text { waist }\end{array}$ \\
\hline Working condition 1 & $\begin{array}{c}\text { Bending moment }(\mathrm{kN} \cdot \mathrm{m}) \\
\text { Axial force }(\mathrm{kN}) \\
\text { Factor of safety }\end{array}$ & $\begin{array}{c}-20.92 \\
-1214.11 \\
16.84\end{array}$ & $\begin{array}{c}-200.25 \\
-5687.47 \\
3.39\end{array}$ & $\begin{array}{l}-170.70 \\
-2524.69 \\
6.83\end{array}$ & $\begin{array}{c}-10.86 \\
-710.27 \\
28.97\end{array}$ & $\begin{array}{c}-365.68 \\
-5789.84 \\
3.01\end{array}$ & $\begin{array}{c}-341.76 \\
-7420.80 \\
2.51\end{array}$ \\
\hline Working condition 2 & $\begin{array}{c}\text { Bending moment }(\mathrm{kN} \cdot \mathrm{m}) \\
\text { Axial force }(\mathrm{kN}) \\
\text { Factor of safety }\end{array}$ & $\begin{array}{c}-19.18 \\
-1089.13 \\
18.75\end{array}$ & $\begin{array}{c}-198.63 \\
-5528.96 \\
3.48\end{array}$ & $\begin{array}{c}-183.21 \\
-2675.42 \\
6.42\end{array}$ & $\begin{array}{c}-12.24 \\
-722.35 \\
28.33\end{array}$ & $\begin{array}{c}-348.82 \\
-5610.71 \\
3.13\end{array}$ & $\begin{array}{c}-339.57 \\
-7258.60 \\
2.56\end{array}$ \\
\hline
\end{tabular}

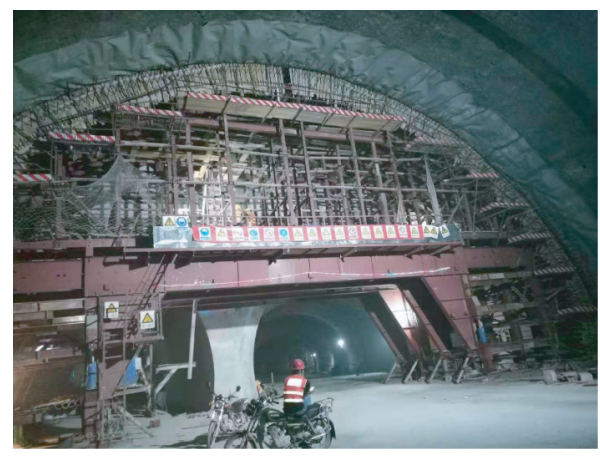

(a)

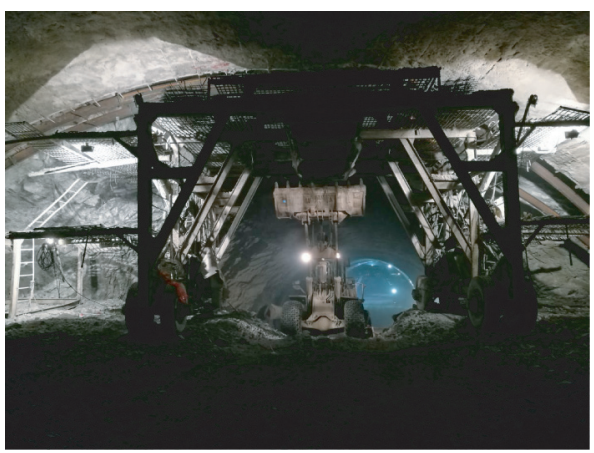

(b)

Figure 8: Field construction of different sections of bifurcated tunnel. (a) On-site construction of small clear-distance section. (b) Largespan site construction.

\section{Conclusions}

By means of theoretical calculation, numerical simulation, and field test, the stability of tunnel surrounding rock under two construction methods of forward and reverse excavation of super large-section bifurcated tunnel is studied. The main conclusions are as follows:
(1) According to the stability criterion of the middle partition wall in the multiarch section and the small clear-distance section, the internal stress and the corresponding ultimate strength of the middle partition wall are calculated under the conditions of different buried depth and thickness of the middle partition wall. It provides a theoretical basis for the 
safe construction of forward and reverse excavation.

(2) Aiming at the problem of insufficient working space for the normal excavation of bifurcated pipe tunnel, the construction method of back excavation after pilot tunnel is demonstrated in detail. The results show that, compared with the original direct excavation scheme, there was no significant difference in ground displacement and internal force distribution in the lining with the pilot tunnel excavation after the reverse excavation method. The ground settlement and safety factor of the lining structure were within the allowable range.

(3) The results show that the designed support measures and the reverse excavation method can effectively ensure the stability of the surrounding rock of the tunnel, which can be used for reference in similar projects.

\section{Data Availability}

The data are available and explained in this article; readers can access the data supporting the conclusions of this study.

\section{Conflicts of Interest}

The authors declare no conflicts of interest. The manuscript was approved by all the authors for publication.

\section{References}

[1] X. L. Li, Z. W. Wang, and F. Jin, "Study on structural optimization of transition section of bell mouth bifurcation tunnel," Value Engineering, vol. 39, no. 2, pp. 168-170, 2020.

[2] S. Z. Wu, "Structure and type selection of large span bifurcated tunnel of Underground Road Interchange in urban core area," Highway Traffic Technology, vol. 34, no. S1, pp. 126-132, 2018.

[3] Y. P. Hu, "Research on key technology of bidirectional construction of large span small clear distance bifurcated tunnel," Railway Construction Technology, vol. 12, pp. 77-80, 2018.

[4] D. M. Cai, "Study on construction method of bifurcated section of long span bifurcated tunnel," Highway Tunnel, vol. 3, pp. 27-32, 2015.

[5] Q. Bi and J. G. Wu, "Research on key technologies for structural design of long span bifurcated tunnel," Tunnel Construction, vol. 31, no. 6, pp. 668-677, 2011.

[6] Q. Liu and T. Y. Qi, "Construction optimization and surface settlement control of large span bifurcated tunnel," Journal of Underground Space and Engineering, vol. 6, no. 5, pp. 10331038, 2010.

[7] Y. J. Jing, Z. Fan, and G. J. Ouyang, “Construction technology of long span bifurcated Xiangjiang tunnel on Yingpan road in Changsha," Tunnel Construction, vol. 33, no. 3, pp. 231-236, 2013.

[8] R. F. Yang and K. Li, "Evaluation standard and method of building deformation under bifurcated tunnel," Highway Engineering, vol. 61, no. 7, pp. 307-313, 2016.
[9] P. Liu, "Key technologies for design and construction of shallow buried bifurcation section of Jiaozhou Bay Tunnel," Tunnel Construction, vol. 33, no. 6, pp. 474-480, 2013.

[10] Q.-X. Meng, W.-Y. Xu, H.-L. Wang, X.-Y. Zhuang, W.-C. Xie, and T. Rabczuk, "DigiSim-an open source software package for heterogeneous material modeling based on digital image processing," Advances in Engineering Software, vol. 148, Article ID 102836, 2020.

[11] Z. G. Tao, C. Zhu, and M. C. He, "A physical modeling-based study on the control mechanisms of Negative Poisson's ratio anchor cable on the stratified toppling deformation of antiinclined slopes," International Journal of Rock Mechanics and Mining Sciences, vol. 138, Article ID 104632, 2021.

[12] C. Zhu, M. He, M. Karakus, X. Zhang, and Z. Tao, "Numerical simulations of the failure process of anaclinal slope physical model and control mechanism of negative Poisson's ratio cable," Bulletin of Engineering Geology and the Environment, vol. 80, no. 4, pp. 3365-3380, 2021.

[13] Z. G. Tao, C. Zhu, and M. C. He, "Research on the safe mining depth of anti-dip bedding slope in Changshanhao Mine," Geomechanics and Geophysics for Geo-Energy and Geo-Resources, vol. 36, no. 6, pp. 1-20, 2020.

[14] Y. Wang, W. K. Feng, R. L. Hu, and C. H. Li, "Fracture evolution and energy characteristics during marble failure under triaxial fatigue cyclic and confining pressure unloading (FC-CPU) conditions," Rock Mechanics and Rock Engineering, vol. 54, no. 2, pp. 799-818, 2021.

[15] B. Li, R. Y. Bao, and Y. Wang, "Permeability evolution of twodimensional fracture networks during shear under constant normal stiffness boundary conditions," Rock Mechanics and Rock Engineering, vol. 54, no. 3, pp. 1-20, 2021.

[16] Q. Wang, H. K. Gao, and B. Jiang, "In-situ test and boltgrouting design evaluation method of underground engineering based on digital drilling," International Journal of Rock Mechanics and Mining Sciences, vol. 138, Article ID 104575, 2021.

[17] Q. Wang, Q. Qin, and B. Jiang, "Mechanized construction of fabricated arches for large-diameter tunnels," Automation in Construction, vol. 124, Article ID 103583, 2021.

[18] A. Li, F. Dai, and Y. Liu, "Dynamic stability evaluation of underground cavern sidewalls against flexural toppling considering excavation-induced damage," Tunnelling and Underground Space Technology, vol. 112, Article ID 103903, 2021.

[19] C. B. Tong and X. H. Niu, "Study on rapid construction technology of urban mountain tunnel with super large section," Construction Technology, vol. 44, no. S2, pp. 424-426, 2015.

[20] S. C. Li, H. P. Wang, and X. F. Zheng, "Forked tunnel stability analysis and its construction optimization research," Chinese Journal of Rock Mechanics and Engineering, vol. 3, pp. 447457, 2008

[21] Ministry of Communications of the People's Republic of China, JTG/TD70-2010 Highway Tunnel Design Rules, People's Communications Press, Beijing, China, 2010. 